\title{
Astragalosides promote angiogenesis via vascular endothelial growth factor and basic fibroblast growth factor in a rat model of myocardial infarction
}

\author{
JUN-MIN YU ${ }^{1}$, XIAO-BO ZHANG ${ }^{1}$, WEN JIANG ${ }^{1}$, \\ HUI-DONG WANG ${ }^{1}$ and YI-NA ZHANG ${ }^{2}$ \\ ${ }^{1}$ Department of Gerontology, The Fourth Clinical Medical College, Harbin Medical University, Harbin, Heilongjiang 150001; \\ ${ }^{2}$ Department of Gerontology, The Second Clinical Medical College, Harbin Medical University, \\ Harbin, Heilongjiang 150086, P.R. China
}

Received November 4, 2014; Accepted July 28, 2015

DOI: $10.3892 / \mathrm{mmr} .2015 .4307$

\begin{abstract}
The aim of the present study was to evaluate the effect of astragalosides (ASTs) on angiogenesis, as well as the expression of vascular endothelial growth factor (VEGF) and basic fibroblast growth factor (bFGF) following myocardial infarction (MI). MI was induced in rats by ligation of the left coronary artery. Twenty-four hours after surgery, the rats were divided into low-dose, high-dose, control and sham surgery groups ( $\mathrm{n}=8$ per group). The low- and high-dose groups were treated with ASTs $(2.5$ and $10 \mathrm{mg} / \mathrm{kg} /$ day, respectively, via intraperitoneal injection), while, the control and sham surgery group rats received saline. Serum levels, and mRNA and protein expression levels of VEGF and bFGF, as well as the microvessel density (MVD) were determined four weeks post-treatment. Twenty-four hours post-surgery, VEGF and bFGF serum levels were observed to be comparable between the groups; while at four weeks, the VEGF and bFGF levels were higher in the AST-treated rats $(\mathrm{P}<0.01)$. Similarly, VEGF and bFGF mRNA and protein expression levels were higher following AST treatment $(\mathrm{P}<0.05)$. No difference in VEGF mRNA expression between the low- and high-dose groups was noted, however, an increase in the bFGF expression levels was detected in the high-dose group. Newly generated blood vessels were observed following MI, with a significant increase in MVD observed in the AST-treated groups $(\mathrm{P}<0.05)$. AST promotes angiogenesis of the heart and increases VEGF and bFGF expression levels. Thus, it is hypothesized that increased VEGF and bFGF levels may contribute to the AST-induced increase in angiogenesis in rat models of MI.
\end{abstract}

Correspondence to: Dr Yi-Na Zhang, Department of Gerontology, The Second Clinical Medical College, Harbin Medical University, 246 Xuefu Street, Harbin, Heilongjiang 150086, P.R. China E-mail: doctor_z_m@126.com

Key words: astragaloside, myocardial infarction, vascular endothelial growth factor, basic fibroblast growth factor, angiogenesis

\section{Introduction}

Coronary heart disease (CHD), a leading cause of mortality worldwide (1), often develops as a result of myocardial ischemia/hypoxia, secondary to coronary atherosclerosis (CAS)-induced stenosis (2). In 2009, the mortality of CHD patients in China was $\sim 94.9 / 100,000$ in cities, which was higher than that in the rural areas $(71.3 / 100,000)(3)$. Furthermore, the rate of mortality attributable to CHD in the USA in 2009 was $236.1 / 100,000$ (4). Although, the overall mortality is lower in the Chinese population, the World Health Organization predicts an increase in the global burden of CHD in China, and the number of patients succumbing to cardiovascular diseases is projected to be $\sim 4$ million by 2020 (5).

In patients with acute myocardial infarction (MI), ventricular arrhythmias may lead to heart failure and finally, mortality (6). The incidence of premature ventricular contraction, ventricular tachycardia and ventricular fibrillation is $\sim 10-93,3-39$ and 4-36\%, respectively $(7,8)$. Currently, $\mathrm{CHD}$ is predominantly treated with therapeutic agents, interventional procedures and surgery with the aim of improving the myocardial ischemia/hypoxia, or controlling the risk factors of CAS, and symptomatically managing the mechanical dysfunction and arrhythmia to maintain a favorable cardiac perfusion $(9,10)$. Despite numerous treatment options, prognosis for the prevention of recurrence of CHD continues to remain poor. Recent advancement in the field of angiogenesis in myocardial ischemia indicates that therapeutic angiogenesis (TA) may promote the growth of blood vessels in the ischemic myocardium, which in turn improves cardiac perfusion $(11,12)$. Improved cardiac perfusion mitigates ischemic tissue necrosis, leading to reduced infarction size, improved left ventricular function and ultimately, survival.

Angiogenic therapy, which involves the use of an exogenous stimulus to promote blood vessel growth, is an attractive approach for the treatment of ischemic diseases (13). It has been demonstrated in experimental models that the stimulation of blood vessel growth leads to growth of the whole vascular tree, improvement of ischemic tissue perfusion and improved muscle aerobic energy metabolism (13). In the progression of $\mathrm{CHD}, \mathrm{MI}-$-induced angiogenesis is a slow process and may only 
partially compensate for the blood supply to the heart following coronary occlusion (11). However, TA further promotes the growth of capillaries and stimulates collateral circulation in the ischemic heart. In recent years, there has been an increased focus on the influence of traditional Chinese medicine (TCM) on angiogenesis (14). It has been identified that TCM stimulates the ischemic heart to produce angiogenic factors, which promote angiogenesis in a paracrine manner (15).

Astragalus is the dry root of Astragalus membranaceus (Fisch) Bge var. mongholicus (Beg) Hsiao or Shanxi Astragalus membranaceus (Fisch) Bge. Astragalus is a sweet herbal supplement, which according to the TCM theory, is known to invigorate the spleen and lungs, and exerts anti-inflammatory and immunomodulatory effects $(16,17)$. Astragalus contains saponins, flavonoids and polysaccharides, of which saponins are the predominant active component.

Astragaloside (AST), is the total saponin fraction isolated from Shanxi Astragalus membranaceus (Fisch) Bge (17), and is usually applied in the prevention and therapy of cardiovascular and cerebrovascular diseases, immune disorders, pulmonary fibrosis, liver cancer, diabetes, kidney disease and for reducing the signs of aging (18). AST inhibits platelet aggregation and causes an increase in prostacyclin and nitric oxide levels, thereby exerting its anti-thrombotic effect. It has been proposed that AST may increase microvessel density (MVD) in the ischemic heart of rats; however, the specific mechanisms remain poorly understood (19). There is evidence demonstrating that AST IV may stimulate angiogenesis of human umbilical vein endothelial cells, which is accompanied by deposition of the hypoxia-inducible factor- $1 \alpha$ protein and transcription of the $V E G F$ gene (20).

VEGF and bFGF are key factors in promoting the growth and differentiation of endothelial cells, and are important in angiogenesis (21). The expression of VEGF and bFGFs and their receptors in capillary endothelial cells is altered in response to pathological conditions, such as ischemia (11). Reduction in oxygen tension leads to activation of these endothelial mitogenic factors and promotes endothelial cell growth. While VEGF (also known as vascular permeability factor) induces differentiation and maturation of endothelial cells, bFGF upregulates the expression of integrins, thereby enhancing cell adhesion and migration, which ultimately results in the formation of new blood vessels $(22,23)$. These two growth factors have been shown to increase regional perfusion, tissue metabolism, improve myocardial function and protect against ischemic damage (13). In the current study, it was hypothesized that AST-induced angiogenesis may be mediated through pro-angiogenic agents, such as VEGF and bFGF. Therefore, the aim of the current study was to investigate the effect of AST on the expression of VEGF and bFGF in the blood and heart of rats following $\mathrm{MI}$, and to investigate the potential underlying mechanisms of AST-induced angiogenesis.

\section{Materials and methods}

Animals. Healthy adult male Wistar rats $(n=45)$ weighing $250 \pm 30 \mathrm{~g}$ were purchased from the Yisi Laboratory Animal Technology Co., Ltd. (Changchun, China) and maintained in a standard care facility with free access to water and food until completion of the study. The rats were treated in accordance with the Guide for the Care (24) and Use of Laboratory Animals published by the US National Institutes of Health. The study was approved by the ethics committee of The Second Affiliated Clinical Medical College of Harbin Medical University (Harbin, China).

Instruments and materials. AST (lot no. MUST-13091001) was obtained from Chengdu Mansite Biology Co., Ltd. (Sichuan, China) and polyclonal rabbit anti-rat VEGF (cat.no.PB0084) and bFGF (cat. no. BA0259) antibodies were purchased from Wuhan Boster Biotech Co., Ltd. (Hubei, China), while the polyclonal rabbit anti-rat VIII antibody (cat. no. bs-0434R) was obtained from Beijing Bo'ao Hengxin Biotech Co., Ltd. (Beijing, China). The ELISA kits for VEGF and bFGF were purchased from R\&D Systems, Inc. (Minneapolis, MN, USA). A small animal ventilator (model, 55-705B) was provided by Harvard University (Cambridge,MA,USA) and the Leica RM2135 rotary microtome was from Leica Microsystems GmbH (Wetzlar, Germany). The image acquisition system (Moticam 3000) was purchased from Motic, Inc., Ltd. (Hong Kong, China) and the Tecan Infinite ${ }^{\circledR}$ Pro 200 microplate reader was obtained from Tecan Schweiz AG, (Männedorf, Switzerland). TRIzol (cat. no. 15596-026) was purchased from Gibco Life Technologies (Carlsbad, CA, USA), and a DyNAmo Flash SYBR Green PCR (cat. no. F-415XL) and reverse transcription kits (cat. no. K1622) were obtained from Thermo Fisher Scientific, Inc. (Waltham, MA, USA). In addition, an Applied Biosystems ${ }^{\circledR}-7500$ Real-Time PCR System (Applied Biosystems Life Technologies, Foster City, CA, USA), X-ray film (cat. no. 6535876; Kodak, Rochester, NY, USA ), a Mini-Protean 3 Electrophoresis system (Bio-Rad, Hercules, CA, USA) and a dark box (Guangdong Yuehua Medical Instrument Factory Co., Ltd., Guangdong, China) were used in the present study.

Induction of MI. Rats were weighed and anesthetized via intraperitoneal (i.p.) injection of $1 \%$ sodium pentobarbital $(40 \mathrm{mg} / \mathrm{kg}$; Merck Millipore, Darmstadt, Germany). Following tracheal intubation, aerobic positive pressure ventilation was performed. An incision was made at the fourth left intercostal space and a thoracotomy was performed. The heart was exposed out of the thoracic cavity by pressing the right thoracic cavity at the back of the pericardium. The left anterior descending coronary artery was ligated, the heart was replaced in the thoracic cavity, and the wound was closed. Upon regaining spontaneous respiration, the tracheal intubation was removed and the rats were returned to their home cages. In the sham surgery group, the coronary artery was exposed using the same protocol, however, it was not ligated.

Grouping. At $24 \mathrm{~h}$ after induction of MI, six rats had succumbed. Subsequently, seven rats succumbed during the experiments; two from each of the control, sham surgery, and low-dose groups, and one rat from the high-dose group. At four weeks, 32 rats remained. Analysis of the causes of mortality in the rats revealed that it may have been caused by insufficient postoperative respiratory care, arrhythmia or heart failure, amongst other factors. The surviving rats were divided into four groups: Low-dose $(n=8)$, high-dose $(n=8)$, control $(n=8)$ and sham surgery $(n=8)$. In the low- and high-dose groups, the rats were administered with 2-ml i.p. injections of AST at 2.5 and $10 \mathrm{mg} / \mathrm{kg} / \mathrm{d}$, respectively. 
In the control and sham surgery groups, normal saline of equal volume was administered via i.p. injection. This treatment was continued for four weeks.

Histological analysis. Four weeks after MI induction and/or AST treatment, the rats were sacrificed and the heart was collected. Briefly, $10 \%$ potassium chloride (Tianjin Kemiou Chemical Reagent Co., Tianjin, China) was injected into the heart to arrest the heart in the diastolic phase. The heart was separated and the atrium, major blood vessels, extracardiac connective tissue and aortic arch were removed. These were rinsed in phosphate-buffered saline (Beijing Solarbio Science \& Technology Co., Ltd., Beijing, China), and dried on filter paper. The left ventricle was weighed on electronic scales and the left ventricular mass index (LVMI) was calculated as follows: Left ventricular weight (mg)/body weight $(\mathrm{g})$. The myocardium was incised at the borderline of the ischemic heart at the cross-sectional level of the papillary muscle, fixed in $10 \%$ neutral formalin solution (Tianjin Kemiou Chemical Reagent Co.) and routine processing for histological examination was then performed. Following a series of dehydration steps in ethanol (Tianjin Kemiou Chemical Reagent Co.), a final tissue clearing in xylene was conducted, and the heart was embedded in paraffin (Tianjin Kemiou Chemical Reagent Co.) and sliced into $4-\mu \mathrm{m}$ sections. The paraffin sections were further processed and stained with hematoxylin and eosin (H\&E; Beyotime Institute of Biotechnology, Shanghai, China), prior to mounting and microscopic evaluation using a light microscope (CH20BIMF200; Olympus, Tokyo, Japan) at x400 magnification.

Detection of serum VEGF and bFGF levels. At $24 \mathrm{~h}$ and four weeks following MI induction, $5 \mathrm{ml}$ blood was collected from the posterior orbital venous plexus, without anticoagulants, and was centrifuged at $1,800 \mathrm{x} \mathrm{g}$ for $10 \mathrm{~min}$. The supernatant was collected and stored at $-80^{\circ} \mathrm{C}$. The serum contents of VEGF and bFGF were measured by ELISA according to the manufacturer's instructions.

Detection of $m R N A$ expression of VEGF and bFGF in the ischemic heart by reverse transcription-quantitative polymerase chain reaction ( $R T-\mathrm{q} P C R)$. Total RNA was extracted according to the manufacturer's instruction and as previously described (25). Briefly, $100 \mathrm{mg}$ heart tissue samples were placed in a $5-\mathrm{ml}$ test tube, followed by the addition of $1 \mathrm{ml}$ cold TRIzol. The heart tissue samples were homogenized and centrifuged according to the manufacturer's instructions. cDNA was then reverse transcribed. RNA (4 $\mu \mathrm{l})$ was thawed and mixed with $5 \mathrm{X}$ reverse transcription buffer $(4 \mu \mathrm{l}), 0.5 \mu \mathrm{l}$ dNTPs, $1 \mu$ l Moloney murine leukemia virus (M-MLV; Thermo Fisher Scientific, Inc.), $0.5 \mu \mathrm{l}$ oligo (dT), and $10 \mu \mathrm{l}$ diethylpyrocarbonate-treated water (total volume, $20 \mu \mathrm{l}$; JRDUN Biotechnology Co., Ltd., Shanghai, China). Reverse transcription was performed at $37^{\circ} \mathrm{C}$ for $1 \mathrm{~h}$ and $95^{\circ} \mathrm{C}$ for $5 \mathrm{~min}$ to inactivate M-MLV. Finally, qPCR was conducted. The obtained cDNA underwent extension by PCR. Data were analyzed using ABI Prism 7300 SDS software (Applied Biosystems Life Technologies,). Data obtained from RT-qPCR were calculated according to the $2^{-\Delta \Delta C t}$ method and experiments were repeated three times. The primers and their corresponding sizes were as follows: Sense, 5'-GAG TCTGTGCTCTGGGATTTG-3' and antisense, 5'-TCCTGC TACCTCTTTCCTCTG-3', for VEGF (length, 188 bps); sense, 5'-TCTGTCTCCCGCACCCTATC-3' and antisense, 5'-ACCAGCCTTCCACCCAAAGC-3' for bFGF (length, 118 bps); and sense, 5'-GTCGGTGTGAACGGATTTG-3' and antisense, 5'-TCCCATTCTCAGCCTTGAC-3' for GAPDH (length, 181 bps).

Detection of VEGF and bFGF protein expression in the heart by western blot assay. The heart tissues were cut into blocks and mixed with lysis buffer (20 mg tissues/150-250 $\mu 1$ lysis buffer; JRDUN Biotechnology Co., Ltd.) containing protease and phosphatase inhibitor, which was followed by homogenization. Following lysis, samples were centrifuged at $4^{\circ} \mathrm{C}$ for $15 \mathrm{~min}$ at $1,800 \mathrm{x} \mathrm{g}$ and the supernatant was collected for protein quantification. Proteins were separated and transferred onto polyvinylidene fluoride membranes (Hangzhou MAILV Filtration Equipment Co., Ltd., Hangzhou, China). Following methanol treatment (Tianjin Kemiou Chemical Reagent Co.), the membranes were washed with Tris-buffered saline and Tween-20 (TBST), and then blocked with skimmed milk powder (JRDUN Biotechnology Co., Ltd.). Subsequently, the membrane was incubated with primary antibody (dilutions: VEGF, 1:1,000; bFGF, 1:300; GAPDH, 1:1,500) according to the manufacturer's instructions. The antibodies were diluted with blocking buffer and incubation of the membranes was conducted at room temperature for $2 \mathrm{~h}$ or at $4^{\circ} \mathrm{C}$ overnight. The membranes were then washed three times with TBST (5-min washes), and treated with horseradish peroxidase-conjugated antibody at $1: 2,000$ at $37^{\circ} \mathrm{C}$ for $1 \mathrm{~h}$. Following three 5-min washes in TBST, visualization was performed using an enhanced chemiluminescence method (EMD Millipore, Billerica, MA, USA). Protein expression was normalized to that of the internal reference (GAPDH) to give the relative expression. The experiments were repeated three times.

Detection of MVD. An immunohistochemical streptavidin-peroxidase method (Beyotime Institute of Biotechnology) was used to detect coagulation factor VIII expression levels in the ischemic heart of the MI rats. Coagulation factor VIII is expressed in the cytoplasm of vascular endothelial cells. According to the method described by Weidner (26), sections were observed under a microscope (magnification, x100) and five fields with a high number of microvessels were selected around the ischemic heart. The microvessels were counted at a magnification of $\mathrm{x} 400$. Three sections were used for analysis in each rat, and five randomly selected fields were selected from each section. The number of microvessels was determined and averaged, and the mean number of microvessels per field was designated as the MVD.

Statistical analysis. Statistical analyses were performed using SPSS 17.0 (SPSS, Inc., Chicago, IL, USA). Continuous variables are presented as means and standard deviations. One-way analysis of variance (ANOVA) with least significant difference post hoc tests were performed to compare the differences between groups. $\mathrm{P}<0.05$ was considered to indicate a statistically significant difference. 
Table I. Weight comparisons between the groups.

\begin{tabular}{|c|c|c|c|c|c|}
\hline Parameter & $\begin{array}{l}\text { Sham surgery } \\
\qquad(\mathrm{n}=8)\end{array}$ & $\begin{array}{c}\text { Control } \\
(n=8)\end{array}$ & $\begin{array}{l}\text { Low-dose } \\
\quad(\mathrm{n}=8)\end{array}$ & $\begin{array}{l}\text { High-dose } \\
\quad(n=8)\end{array}$ & P-value \\
\hline Weight (g) & $315.44 \pm 4.56$ & $310.05 \pm 8.72$ & $317.10 \pm 10.03$ & $316.84 \pm 6.58$ & 0.253 \\
\hline Left ventricular mass (mg) & $653.04 \pm 45.46$ & $850.44 \pm 32.00^{\mathrm{a}}$ & $811.95 \pm 25.41^{\mathrm{a}, \mathrm{b}}$ & $786.81 \pm 31.14^{\mathrm{a}, \mathrm{b}}$ & $<0.001$ \\
\hline Left ventricular mass index (mg/g) & $2.07 \pm 0.14$ & $2.75 \pm 0.13^{\mathrm{a}}$ & $2.56 \pm 0.07^{\mathrm{a}, \mathrm{b}}$ & $2.49 \pm 0.11^{\mathrm{a}, \mathrm{b}}$ & $<0.001$ \\
\hline
\end{tabular}

${ }^{\mathrm{a}} \mathrm{P}<0.05$ vs. the sham surgery group; ${ }^{\mathrm{b}} \mathrm{P}<0.05$ vs. the control group.
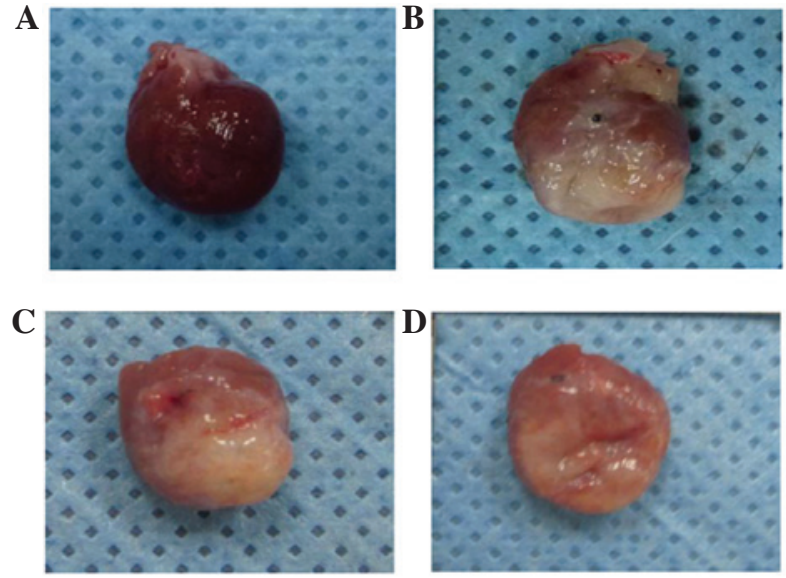

Figure 1. Infarct size of rats four weeks subsequent to induction of myocardial infarction. (A) Rat heart specimen of sham surgery group, (B) Rat heart specimen of control group, (C) Rat heart specimen of low-dose astragaloside group, revealing light yellow color in the lesion tissue and blur boundaries between normal and lesion tissue and (D) Rat heart specimen of high-dose astragaloside group, demonstrating that the color of the lesion site was slightly different from the normal tissue, and the light yellow region was markedly smaller than hearts in other groups. In the ischemic heart, the myocardium exhibited disordered arrangement. In the non-ischemic heart, the myocardium exhibited ordered arrangement and a small quantity of inflammatory cell infiltration. In the ischemic heart, the myocardial cells were lysed and fractured, the myocardial structure was disordered, the nucleus was absent and there was infiltration of fibroblasts. There was a clear boundary between the ischemic heart and the intact heart.
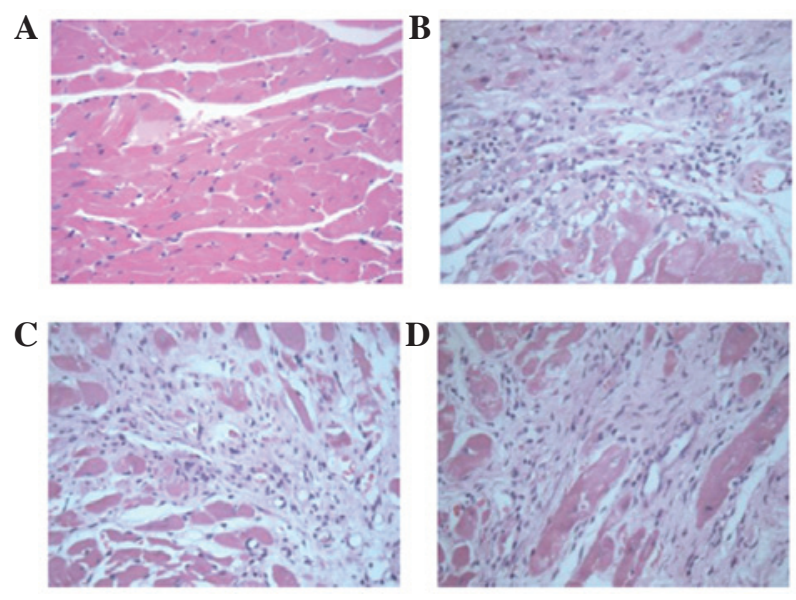

Figure 2. Histomorphological results of hematoxylin and eosin staining in rat heart tissue samples. (A) Sham surgery, the myocardial structure had an ordered arrangement and a small number of inflammatory cells were observed. (B) Control, in the infarct zone the myocardial structure was disordered, cardiomyocyte lysis occurred and striated muscle was fractured with a large number of inflammatory cells. In the non-infarct zone the myocardial structure had an ordered arrangement and there was a clear boundary between the infarcted area and non-infarcted area. (C) Low-dose group, the myocardial structure was disordered with inflammatory cell infiltration. (D) High-dose group, the myocardial structure was disordered with inflammatory cell infiltration. Magnification, x400.

\section{Results}

Gross cardiac morphology, pathological myocardial changes and changes in left ventricular mass in rats. LVMI is an important indicator of myocardial hypertrophy (27). Following MI, cardiomyocyte hypertrophy is an important feature of myocardial remodeling and is involved in the occurrence and development of heart failure. Thus, therapeutic modalities, 
Table II. Comparisons between groups at various time points in serum VEGF and bFGF levels.

A, Serum VEGF

\begin{tabular}{|c|c|c|c|c|c|}
\hline \multirow[b]{2}{*}{ Time point } & \multicolumn{4}{|c|}{ Serum level (pg/ml) } & \multirow[b]{2}{*}{ P-value } \\
\hline & $\begin{array}{l}\text { Sham surgery } \\
\qquad(\mathrm{n}=8)\end{array}$ & $\begin{array}{c}\text { Control } \\
(n=8)\end{array}$ & $\begin{array}{l}\text { Low-dose } \\
\qquad(\mathrm{n}=8)\end{array}$ & $\begin{array}{l}\text { High-dose } \\
\qquad(\mathrm{n}=8)\end{array}$ & \\
\hline $24 \mathrm{~h}$ after surgery & $92.36 \pm 13.06$ & $93.78 \pm 13.28$ & $95.86 \pm 6.10$ & $96.52 \pm 11.60$ & 0.878 \\
\hline 4 weeks after surgery & $90.24 \pm 7.08$ & $93.04 \pm 13.08$ & $109.79 \pm 10.74^{\mathrm{a}, \mathrm{b}}$ & $115.10 \pm 12.21^{\mathrm{a}, \mathrm{b}}$ & $<0.001$ \\
\hline
\end{tabular}

B, Serum bFGF

\begin{tabular}{|c|c|c|c|c|c|}
\hline \multirow[b]{2}{*}{ Time point } & \multicolumn{4}{|c|}{ Serum level (pg/ml) } & \multirow[b]{2}{*}{ P-value } \\
\hline & $\begin{array}{l}\text { Sham surgery } \\
\qquad(n=8)\end{array}$ & $\begin{array}{c}\text { Control } \\
(n=8)\end{array}$ & $\begin{array}{l}\text { Low-dose } \\
\qquad(\mathrm{n}=8)\end{array}$ & $\begin{array}{l}\text { High-dose } \\
\qquad(\mathrm{n}=8)\end{array}$ & \\
\hline $24 \mathrm{~h}$ after surgery & $5.17 \pm 1.99$ & $4.77 \pm 1.70$ & $4.78 \pm 2.13$ & $5.31 \pm 2.20$ & 0.932 \\
\hline 4 weeks after surgery & $4.69 \pm 2.32$ & $4.32 \pm 1.23$ & $9.00 \pm 2.37^{\mathrm{a}, \mathrm{b}}$ & $9.56 \pm 2.93^{\mathrm{a}, \mathrm{b}}$ & $<0.001$ \\
\hline
\end{tabular}

${ }^{\mathrm{a}} \mathrm{P}<0.05$ vs. the sham surgery group; ${ }^{\mathrm{b}} \mathrm{P}<0.05$ vs. the control group. VEGF, vascular endothelial growth factor; bFGF, basic fibroblast growth factor.

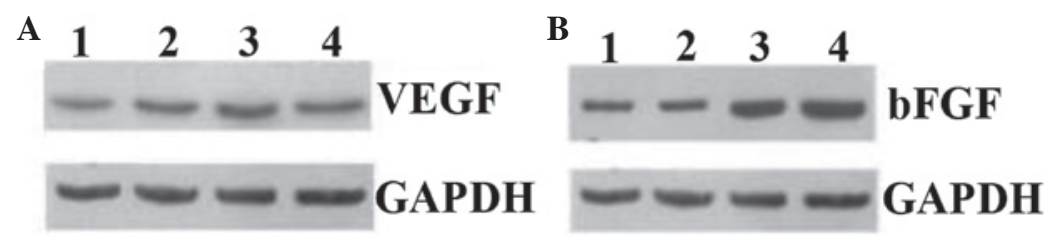

Figure 3. Protein expression in ischemic myocardium rat samples: (A) VEGF and (B) bFGF. Lanes 1-4 represent the sham surgery, control, low-dose and high-dose groups, respectively. VEGF, vascular endothelial growth factor; bFGF, basic fibroblast growth factor.

which target pathological cardiomyocyte hypertrophy are crucial for the prevention of myocardial remodeling, and the occurrence and development of heart failure (28). On completion of the study, the rats were sacrificed and their hearts were collected. Macroscopic observations revealed grey infarct regions of different sizes. The mean left ventricular mass and LVMI were found to be significantly higher in the control, and low- and high-dose groups when compared with the sham surgery group (left ventricular mass: 850.44, 811.95 and $786.81 \mathrm{mg}$ vs. $653.04 \mathrm{mg}$, respectively; $\mathrm{P}<0.001$. LVMI: 2.75, 2.56 and $2.49 \mathrm{mg} / \mathrm{g}$ vs. $2.07 \mathrm{mg} / \mathrm{g} ; \mathrm{P}<0.001)$. Furthermore, the mean left ventricular mass and LVMI were significantly higher in the control group when compared with the low- and high-dose groups (left ventricular mass: $850.44 \mathrm{mg}$ vs. 811.95 and $786.81 \mathrm{mg} ; \mathrm{P} \leq 0.033$. LVMI: $2.75 \mathrm{mg} / \mathrm{g}$ vs. 2.56 and $2.49 \mathrm{mg} / \mathrm{g} ; \mathrm{P} \leq 0.003)$. There were no significant differences identified between the groups with regard to rat weight (Fig. 1 and Table I).

The pathological changes in the myocardium were examined by H\&E staining of the heart. At four weeks after induction of MI, samples of heart tissue were collected for H\&E staining. Under a light microscope, the myocardium revealed ordered arrangement and a small number of inflammatory cells, which had infiltrated into the heart in the sham surgery group. In the control group and low- and high- dose group, the cardiomyocytes were lysed or fractured, the myocardial structure was disordered, their nuclei were absent, and a small quantity of fibroblasts had infiltrated into the heart. There was a clear boundary between the infarct region and the intact region (Fig. 2).

Serum levels of VEGF and bFGF among the groups at different time points. A comparison between the different groups of VEGF and bFGF serum levels is presented in Table II. No significant differences were noted between the sham surgery, the control, and the low- and high-dose groups in serum VEGF and bFGF levels $24 \mathrm{~h}$ after surgery ( $\mathrm{P}>0.05)$.

The mean serum VEGF and bFGF levels (Table II) four weeks after surgery were significantly higher in the low- and high-dose groups, as compared with those in the sham surgery and control groups (serum VEGF: 109.79 and $115.1 \mathrm{pg} / \mathrm{ml}$ vs. 90.24 and $93.04 \mathrm{pg} / \mathrm{ml} ; \mathrm{P} \leq 0.005$. Serum bFGF: 9 and $9.56 \mathrm{pg} / \mathrm{ml}$ vs. 4.69 and $4.32 \mathrm{pg} / \mathrm{ml}$; $\mathrm{P} \leq 0.001)$.

$m R N A$ and protein expression levels of VEGF and bFGF in the four groups. The mean VEGF mRNA levels were significantly higher in the low- and high-dose groups, compared with those in the sham surgery and control groups $(0.015$ and 0.02 vs. 0.003 and $0.002 ; \mathrm{P} \leq 0.012$ ). Similarly, the mean bFGF mRNA level was significantly higher in the high-dose 
Table III. Comparisons between groups in MVD, VEGF and bFGF protein expression, and VEGF and bFGF mRNA expression.

A, Myocardial infarction marginal zone

\begin{tabular}{|c|c|c|c|c|c|}
\hline Parameter & $\begin{array}{l}\text { Sham surgery } \\
\qquad(\mathrm{n}=8)\end{array}$ & $\begin{array}{l}\text { Control } \\
(n=8)\end{array}$ & $\begin{array}{l}\text { Low-dose } \\
\quad(n=8)\end{array}$ & $\begin{array}{l}\text { High-dose } \\
\qquad(\mathrm{n}=8)\end{array}$ & P-value \\
\hline MVD (per visual field) & $5.25 \pm 1.39$ & $20.5 \pm 5.24^{\mathrm{a}}$ & $26.88 \pm 4.32^{\mathrm{a}, \mathrm{b}}$ & $29.88 \pm 3.36^{\mathrm{a}, \mathrm{b}}$ & $<0.001$ \\
\hline VEGF protein expression & $0.23 \pm 0.15$ & $0.25 \pm 0.13$ & $0.52 \pm 0.27^{\mathrm{a}, \mathrm{b}}$ & $0.58 \pm 0.36^{\mathrm{a}, \mathrm{b}}$ & 0.015 \\
\hline bFGF protein expression & $0.48 \pm 0.13$ & $0.62 \pm 0.14$ & $0.88 \pm 0.19^{\mathrm{a}, \mathrm{b}}$ & $0.88 \pm 0.42^{\mathrm{a}, \mathrm{b}}$ & 0.006 \\
\hline
\end{tabular}

$\mathrm{B}$, Ischemic myocardium

\begin{tabular}{|c|c|c|c|c|c|}
\hline Parameter & $\begin{array}{l}\text { Sham surgery } \\
\qquad(\mathrm{n}=8)\end{array}$ & $\begin{array}{l}\text { Control } \\
(n=8)\end{array}$ & $\begin{array}{l}\text { Low-dose } \\
\quad(n=8)\end{array}$ & $\begin{array}{l}\text { High-dose } \\
\qquad(\mathrm{n}=8)\end{array}$ & P-value \\
\hline VEGF mRNA expression & $0.003 \pm 0.004$ & $0.002 \pm 0.003$ & $0.015 \pm 0.007^{\mathrm{a}, \mathrm{b}}$ & $0.02 \pm 0.015^{\mathrm{a}, \mathrm{b}}$ & $<0.001$ \\
\hline bFGF mRNA expression & $0.003 \pm 0.003$ & $0.003 \pm 0.003$ & $0.010 \pm 0.008$ & $0.019 \pm 0.014^{\mathrm{a}, \mathrm{b}, \mathrm{c}}$ & 0.013 \\
\hline
\end{tabular}

${ }^{a} \mathrm{P}<0.05$ vs. the sham operation group. ${ }^{b} \mathrm{P}<0.05$ vs. the control group. ${ }^{\mathrm{c}} \mathrm{P}<0.05$ vs. the low-dose group. MVD, microvessel density; VEGF, vascular endothelial growth factor; bFGF, basic fibroblast growth factor.
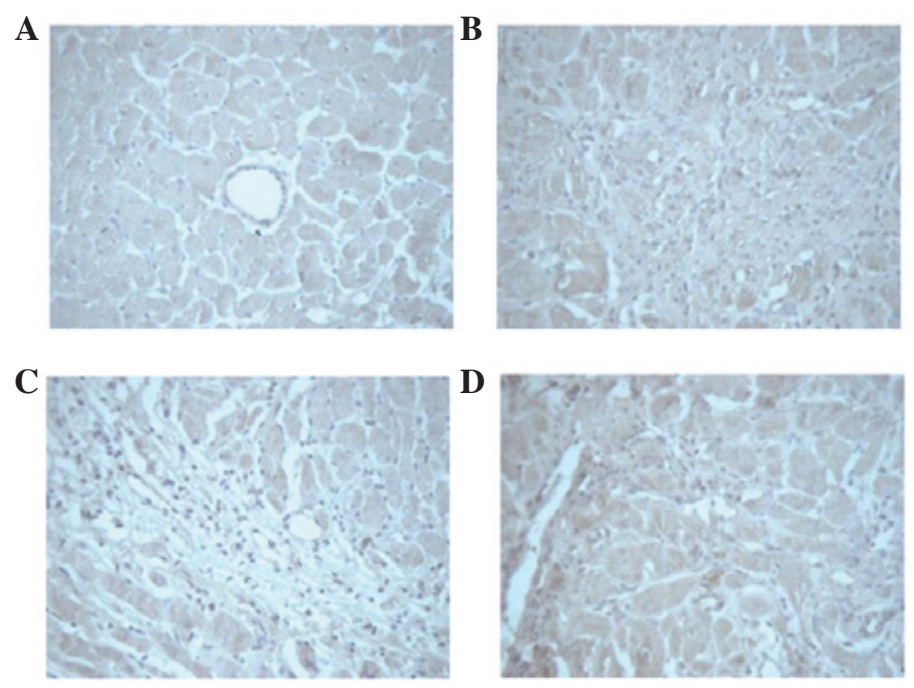

Figure 4. Immunohistochemical staining revealing expression of coagulation factor VIII in the ischemic myocardium of rats from the (A) sham surgery, (B) control, (C) low-dose and (D) high-dose groups (magnification, $\mathrm{x} 400$ ).

group, as compared with that in the sham surgery, control and low-dose groups (0.019 vs. $0.003,0.003$ and 0.010 ; $\mathrm{P} \leq 0.028$ ) (Table III). However, in contrast to the VEGF mRNA levels, a dose-dependent effect of AST was observed in the bFGF mRNA levels, with a significantly higher mRNA expression level observed in the high-dose group compared with the low-dose group $(0.019 \pm 0.014$ vs. $0.010 \pm 0.008)$.

Similar to the mRNA expression levels, VEGF and bFGF protein expression (Table III and Fig. 3) were significantly higher in the AST-treated rats (low- and high-dose), as compared with those in the sham surgery and control groups (VEGF: 0.52 and 0.58 vs. 0.23 and 0.25 ; $\mathrm{P} \leq 0.039$. bFGF: 0.88 and 0.88 vs. 0.48 and $0.62 ; \mathrm{P} \leq 0.049$ ). Although a dose-dependent increase was observed in the bFGF mRNA expression levels, no such change in bFGF protein expression was identified between the two AST treatment groups.

MI induces an increase in MVD. At four weeks following pharmacotherapy, immunohistochemistry was conducted to identify coagulation factor VIII. The newly generated capillaries were observed in the myocardium of rats in all of the groups, particularly at the border of the infarct region (Fig. 4). The MVD was calculated in the surrounding margin of the infarct regions (Table III). The mean MVD, as indicated by the expression of coagulation factor VIII (Table III; Fig. 4), was significantly greater in the control, and the low- and high-dose groups, when compared with that of the sham surgery group $(20.5,26.88$ and 29.88 vs. 5.25/visual field; $\mathrm{P}<0.001)$. When compared with the control group, the 
MVD was observed to be significantly higher in the low- and high-dose groups (26.88 and 29.88 vs. 20.5/visual field; $\mathrm{P} \leq 0.003)$.

\section{Discussion}

In the present study, the effect of AST (daily treatment for four weeks) was evaluated in a rat model of MI. The results indicate that AST offers substantial cardioprotection in MI rats. Increases in MVD, observed in AST-treated rats, may indicate angiogenesis and improved collateral circulation. Furthermore, the serum levels and mRNA/protein expression levels of VEGF and bFGF were significantly higher in the AST-treated rats. Although no dose-dependent effect was observed in the mRNA expression levels of VEGF, increased bFGF mRNA expression levels were identified in the high-dose group (10 mg/kg/day AST). Taken together, the current results indicate that AST improves cardiac function via upregulation of VEGF and bFGF, which subsequently stimulates angiogenesis in the MI heart.

Angiogenesis is a physiological process through which new blood vessels form from pre-existing vessels by budding in response to angiogenic signals, such as hypoxia, growth factors, or vasodilators. In addition, angiogenesis is involved in the formation of new blood vessels during embryonic development, as well as in tissue repair and tumorigenesis $(11,29)$. Angiogenesis is crucial in myocardial tissue repair following MI. The present study demonstrates a considerable change in LVMI and necrosis in AST-treated rats (Figs. 1 and 2), indicating that AST inhibits or reduces myocardial hypertrophy, and thus prompts cardioprotection. Similarly, a significant increase in MVD was also observed in the AST-treated rats, when compared with the control and sham surgery group rats (Table III; P $\leq 0.015$ by one-way ANOVA with Bonferroni post hoc tests). These findings indicate that AST promotes angiogenesis in the heart of MI rats, which is consistent with previous studies $(19,20)$.

Increases in MVD in the heart may reflect the formation of coronary collateral circulation to a certain extent. Following MI, the formation of collateral circulation requires the stimulation of quiescent endothelial cells by various growth factors, including VEGF and bFGF. The role of VEGF and bFGF in angiogenesis is well understood $(30,31)$. VEGF proteins are homodimeric, with two subunits of $\sim 120-200$ amino acids in length, and bind to Fms-like tyrosine and fetal liver kinase-1/kinase insert domain receptor on the endothelial cells (32) to stimulate proliferation of the endothelial cells to form new microvessels (31). bFGF, however, mediates the expression of integrins, enhances cell adhesion and migration of vascular endothelial and smooth muscle cells, promotes the formation of new blood vessels and increases collateral circulation $(22,23,33)$.

De novo formation of microvessels has the potential to salvage ischemic myocardium in the early stages following $\mathrm{MI}$, and is also essential for long-term left ventricular remodeling to prevent the transition to heart failure (29). Although the existence of collateral circulation in CHD patients is associated with improved clinical outcomes, the net effect is not sufficiently adequate to compensate for the flow lost as a result of occlusion of the native coronary arteries (11). The use of a therapeutic agent that further accelerates collateral vessel growth may prove to be particularly beneficial in controlling CHD worldwide. Although experimental studies on the stimulation of angiogenesis have been promising, to the best of our knowledge, no single therapeutic agent has been identified as applicable in clinical practice, either due to a lack of efficacy or negative side effects (34).

AST is a type of TCM, which has been used for centuries and implicated in the stimulation of angiogenesis; furthermore, its safety and efficacy have been well established in various models (17-20). The findings of the present study validate the administration of AST in MI to alleviate the deleterious consequences of ischemia. Daily AST treatment for four weeks induced a marked increase in the serum VEGF and bFGF levels (at $24 \mathrm{~h}$ ), when compared with the baseline levels and was significantly different from the control and the sham surgery groups $(\mathrm{P}<0.05$; Table II). In addition, a clear increase in the mRNA and protein expression levels of VEGF and bFGF was observed in the AST-treated rats, when compared with the control group $(\mathrm{P}<0.05$; Table III and Fig. 3), indicating that AST induced the upregulation of these endothelial mitogenic factors. Though no dose-dependent effect of AST was noted in the serum level or the mRNA/protein expression levels of VEGF, a significant increase in the level of bFGF mRNA expression was observed at the higher dose of AST (10 mg/kg/day). However, this apparent increase in bFGF mRNA was not translated to the protein levels (Table III), therefore, it is challenging to establish whether there is a dose-dependent effect of AST on these parameters. It is proposed that a dose-dependent effect may be more evident at a higher dose than that which was used in the current study.

The increase in MVD, as represented by the increase in coagulation factor VIII expression (Fig. 4), provides further evidence for AST-induced angiogenesis and myocardial protection. A significant increase was observed in the MVD per visual field in AST-treated rats, when compared with the control and the sham surgery group rats $(\mathrm{P}<0.05$; Table III). However, no significant difference between the two different AST dose groups was identified, which may be attributed to the slight variability in demarcating the ischemic heart tissue, which was collected for histological analysis, or due to the procedures that were used for MVD detection.

In a normal myocardium, only traces of VEGF and bFGF expression are observed. However, numerous clinical and experimental procedures, such as artificial heart surgery, myocardial ischemia, hypoxia, thoracotomy and anesthesia may induce feedback mechanisms and cause increases in the expression of VEGF and bFGF, which may have affected the outcomes of the current study. This presents a study limitation; however, care was taken during the current study regarding the surgical methods and attempts were made to maintain the inter-group variability at a minimum. An additional limitation of the present study is that growth of microcirculation in experimental animals may vary between species and the results may not correlate with a different animal model, such as a porcine or dog model of MI.

Collectively, the present data indicate that AST promotes angiogenesis in the heart of MI-induced rats, which may be ascribed to the upregulation of VEGF and bFGF levels 
in the blood and heart tissue. Experimental studies on in vitro and in vivo models have demonstrated that the pro-angiogenic effects of AST are mediated through VEGF and downstream Akt signaling pathways (35). Recent identification of a novel VEGF, Notch/Jagged-1, that directly transmits the Jagged-1/Notch signals to cells to regulate the VEGFR3-associated angiogenesis $(36,37)$, indicates that there are additional mechanisms involved. However, although the functions of Notch and VEGF are different, the two are complementary in tumor angiogenesis (38). Establishing whether such a complementary role exists in myocardial angiogenesis may be of interest for future studies.

In conclusion, AST stimulates MI-induced angiogenesis of the heart, via the upregulation of endothelial mitogenic factors, including VEGF and bFGF. However, the involvement of additional signaling pathways in AST-induced angiogenesis cannot be disregarded and further studies are required to extend the understanding of the mechanism of action of this well-established TCM.

\section{Acknowledgements}

The present study was supported by the Science and Technology Research Project of Department of Education of Heilongjiang Province. (grant no. 12521297).

\section{References}

1. Orphanou K, Stassopoulou A and Keravnou E: Risk assessment for primary coronary heart disease event using dynamic Bayesian networks. In: Artificial Intelligence in Medicine. Holmes J, Bellazzi R, Sacchi L and Peek N (eds). Vol 9105. Springer International Publishing, pp161-165, 2015.

2. Liu Y and Liu RX: The research progress of Traditional Chinese medicine in treatment of coronary atherosclerosis heart disease. Hebei J of Trad Chin Med 35: 1476-1478, 2013 (In Chinese).

3. Tao HM, Qin S and Zhang DY: Research progress of coronary heart disease in women. Adv Cardiovasc Dis 35: 250-253, 2014 (In Chinese).

4. Go AS, Mozaffarian D, Roger VL, Benjamin EJ, Berry JD, Borden WB, Bravata DM, Dai S, Ford ES, Fox CS, et al: Executive summary: Heart disease and stroke statistics-2013 update: A report from the American heart association. Circulation 127: $143-152,2013$.

5. Li XY and Fu ZQ: Pharmacotherapy of coronary heart disease in the elderly. J Med Res 40: 3-5, 2011 (In Chinese).

6. de bakker JM, van capelle FJ, Janse MJ, Wilde AA, Coronel R, Becker AE, Dingemans KP, van Hemel NM and Hauer RN: Reentry as a cause of ventricular tachycardia in patients with chronic ischemic heart disease: Electrophysiologic and anatomic correlation. Circulation 77: 589-606, 1988.

7. Wang LM, Zhang SD and Ann YC: Treatment of ventricular arrhythmia after myocardial infarction. Chinese Journal of Cardiovascular Review 6: 144-146, 2008 (In Chinese).

8. Meng QC: Treatment and prevention of reperfusion arrhythmia after thrombolytic therapy for acute myocardial infarction. Journal of Medical Forum 27: 55-57, 2006 (In Chinese).

9. Bates ER and Topol EJ: Limitations of thrombolytic therapy for acute myocardial infarction complicated by congestive heart failure and cardiogenic shock. J Am Coll Cardiol 18: 1077-1084, 1991.

10. Kones R: Primary prevention of coronary heart disease: Integration of new data, evolving views, revised goals and role of rosuvastatin in management. A comprehensive survey. Drug Des Devel Ther 5: 325-380, 2011.

11. Ware JA and Simons M: Angiogenesis in ischemicheart disease. Nat Med 3: 158-164, 1997.
12. Rissanen TT, Korpisalo P, Markkanen JE, Liimatainen T, Ordén MR, Kholová I, de Goede A, Heikura T, Gröhn OH and Ylä-Herttuala S: Blood flow remodels growing vasculature during vascular endothelial growth factor gene therapy and determines between capillary arterialization and sprouting angiogenesis. Circulation 112: 3937-3946, 2005.

13. Dragneva G, Korpisalo P and Ylä-Herttuala S: Promoting blood vessel growth in ischemic diseases: Challenges in translating preclinical potential into clinical success. Dis Model Mech 6: 312-322, 2013.

14. Liu Q, Li J, Wang J, Li J, Janicki JS and Fan D: Effects and mechanisms of Chinese herbal medicine in ameliorating myocardial ischemia-reperfusion injury. Evid Based Complement Alternat Med 2013: 925625, 2013.

15. Liu YF, Liu SW and Liu ZX: Effects of Ginsenosiee Rb1 on blood vessel regeneration after ischemia and reperfusion in rats. Chin J Histochem Cytochem 17: 39-44, 2008 (In Chinese).

16. Han D, Zhang Y, Liu M, et al: The hemodynamic and antioxidant effects of Astragaloside on ventricular remodeling rats. Chin J Lab Diag 17: 1956-1959, 2013 (In Chinese).

17. Wang YP, Li XY, Song CQ and Hu ZB: Effect of astragaloside IV on T, B lymphocyte proliferation and peritoneal macrophage function in mice. Acta Pharmacol Sin 23: 263-266, 2002.

18. Yin Y, Li WP, Gong HL, Zhu FF, Li WZ and Wu GC: Protective effect of astragaloside on focal cerebral ischemia/reperfusion injury in rats. Am J Chin Med 38: 517-527, 2010.

19. Yang JS, Yu JM, Ju L, et al: Effects of Astragalosides on angiogenesis in myocardium infarction rats. Chin J Prim Med Pharm 19: 215-217, 2012.

20. Zhang L, Liu Q, Lu L, Zhao X, Gao X and Wang Y: Astragaloside IV stimulates angiogenesis and increases hypoxia-inducible factor-1 $\alpha$ accumulation via phosphatidylinositol 3-kinase/Akt pathway. J Pharmacol Exp Ther 338: 485-491, 2011.

21. De Luca A, Carotenuto A, Rachiglio A, Gallo M, Maiello MR, Aldinucci D, Pinto A and Normanno N: The role of the EGFR signaling in tumor microenvironment. J Cell Physiol 214: 559-567, 2008.

22. Böttcher RT and Niehrs C: Fibroblast growth factor signaling during early vertebrate development. Endocr Rev 26: 63-77, 2005.

23. Andersson $\mathrm{H}$ and Brittebo E: Proangiogenic effects of environmentally relevant levels of bisphenol A in human primary endothelial cells. Arch Toxicol 86: 465-474, 2012.

24. Clark JD, Gebhart GF, Gonder JC, Keeling ME and Kohn DF: Special Report: The 1996 Guide for the Care and Use of Laboratory Animals. ILAR J 38: 41-48, 1997.

25. Reddy BY, Greco SJ, Patel PS, Trzaska KA and Rameshwar P: RE-1-silencing transcription factor shows tumor-suppressor functions and negatively regulates the oncogenic TAC 1 in breast cancer cells. Proc Natl Acad Sci U S A 106: 4408-4413, 2009.

26. Weidner N: Intratumor microvessel density as a prognostic factor in cancer. Am J Pathol 147: 9-19, 1995.

27. Aurgemma GP and Gaasch WH: Quantitative evaluation of left ventricular structure, wall stress, and systolic function. In: The Practice of Clinical Echocardiography. Otto CM (ed). 2nd edition. Elsevier Saunders, Philadelphia, PA, pp65-87, 2002.

28. Meiners S, Dreger H, Fechner M, Bieler S, Rother W, Günther C, Baumann G, Stangl V and Stangl K: Suppression of cardiomyocyte hypertrophy by inhibition of the ubiquitin-proteasome system. Hypertension 51: 302-308, 2008.

29. Cochain C, Channon KM and Silvestre JS: Angiogenesis in the infarcted myocardium. Antioxid Redox Signal 18: 1100-1113, 2013.

30. Hicklin DJ and Ellis LM: Role of the vascular endothelial growth factor pathway in tumor growth and angiogenesis. J Clin Oncol 23: 1011-1027, 2005.

31. Pohl-Schickinger A, Koehne P, Schmitz T, Schmitt KR, Hübler M, Redlin M, Berger F and Stiller B: Vascular endothelial growth factor and its soluble receptor in infants with congenital cardiac disease. Cardiol Young 20: 505-508, 2010.

32. Shibuya M: VEGF-VEGFR signals in health and disease. Biomol Ther 22: 1-9, 2014. 
33. Wafai R, Tudor EM, Angus JA and Wright CE: Vascular effects of FGF-2and VEGF-B in rabbits with bilateral hind limb ischemia. J Vasc Res 46: 45-54, 2009.

34. Schirmer SH, van Nooijen FC, Piek JJ and van Royen N: Stimulation of collateral artery growth: Travelling further down the road to clinical application. Heart 95: 191-197, 2009.

35. Zhang Y, Hu G, Li S, Li ZH, Lam CO, Hong SJ, Kwan YW, Chan SW, Leung GP and Lee SM: Pro-angiogenic activity of astragaloside IV in HUVECs in vitro and zebrafish in vivo. Mol Med Rep 5: 805-811, 2012.
36. Karanu FN, Murdoch B, Gallacher L,Wu DM, Koremoto M, Sakano S and Bhatia M: The notch ligand jagged-1 represents a novel growth factor of human hematopoietic stem cells. J Exp Med 192: 1365-1372, 2000.

37. Benedito R, Roca C, Sörensen I, Adams S, Gossler A, Fruttiger M and Adams RH: The notch ligands D114 and Jagged1 have opposing effects on angiogenesis. Cell 137: 1124-1135, 2009.

38. Hernandez SL, Banerjee D, Garcia A, Kangsamaksin T, Cheng WY, Anastassiou D, Funahashi Y, Kadenhe-Chiweshe A, Shawber CJ, Kitajewski JK, et al: Notch and VEGF pathways play distinct but complementary roles in tumor angiogenesis. Vasc Cell 5: 17, 2013. 